\title{
NUMERICAL SIMULATION ANDCONSTRUCTAL DESIGN APPLIED TO THE STUDY OF ELASTIC BUCKLING IN THIN STEEL PLATES WITH OBLONG PERFORATIONS
}

\author{
Emilio Gabriel Gonçalves Folzke ${ }^{1}$, Thiago da Silveira ${ }^{1}$, João Paulo Silva Lima ${ }^{1}$, Luiz \\ Alberto Oliveira Rocha ${ }^{2}$, Elizaldo Domingues dos Santos ${ }^{1}$, Mauro de Vasconcellos Real ${ }^{1}$ \& \\ Liércio André Isoldi ${ }^{*}$
}

\begin{abstract}
FOLZKE, E.G.G.; SILVEIRA, T.; LIMA, J.P.S.; ROCHA, L.A.O.; SANTOS, E.D.; REAL, M.V.; ISOLDI, L.A. Numerical simulation andconstructal design applied to the study of elastic buckling in thin steel plates with oblong perforations. Perspectivas Online: Exatas \& Engenharias, v. 8, n.20, p.127-138,2018.
\end{abstract}

Buckling is an instability phenomenon that can happen when a slender plate is subjected to axial compression loads. In addition, perforated plates are often necessary in the engineering field. Throughout this article, the Constructal Design Method, which is based on the Constructal Theory, has been used to evaluate the influence of the hole on thin steel plates under elastic buckling. For that, the different types of holes analyzed were both transversal and longitudinal oblong. They were all placed in the center of the plate. The geometry of the hole varied according to the degree of freedom $H_{0} / L_{0}$, which relates the dimensions of each type of different hole. The size of the perforation are varied by means the hole volume fraction $(\phi)$ parameter, that represents the relation between the volume of the hole and the total volume of the plate (without hole). The main goal is to achieve the greatest critical load for the perforated plates. To do so, the ANSYS software, based on the Finite Element Method (FEM), has been used to numerically analyze the elastic buckling in each case. It has been observed the importance of the geometry when seeking superior performances: through a simple fluctuation of the geometry of the hole, once the volume fraction was kept constant, it was possible to achieve a significant increase on the critical loads.

Key words: Buckling; Computational Modeling; Critical Load; Constructal Design.

\footnotetext{
${ }^{1}$ Universidade Federal do Rio Grande, FURG - Instituto de Oceanografia,Campus Carreiros, Avenida Itália, Km 8, s/n Carreiros, Rio Grande, RS, CEP: 96201-900,Brasil

${ }^{2}$ Universidade Federal do Rio Grande do Sul, UFRGS - Av. Paulo Gama, 110, Farroupilha, Porto Alegre, RS, $90040-$ 060, Brasil.

(*)e-mail: liercioisoldi@furg.br

Data de chegada: 07/05/2017 Aceito para publicação: 29/05/2017
}

Persp. Online: exatas \& eng., Campos dos Goytacazes, 20 (08) 127-138 - 2018 


\section{INTRODUCTION}

Whenever a structural element has two dimensions much larger than one, and is plane before any load is applied on it, it is called a plate (YAMAGUCHI, 1999). Thin elements, such as a slender plate, can be subjected to several different types of deformation. Among them, there is buckling, which is an instability phenomenon that can occur if a slender and thin-walled plate (plane or curved) is subjected to axial pressure (i.e. compression). At a certain given critical load, the plate will buckle suddenly in the out-of-plane transverse direction (AKESSON, 2007).

Thin plates are widely used in different engineering areas such as oceanic and naval. Nevertheless, sometimes, the plates need to be perforated in order to reduce the structure's weight, to grant access and even to improve aesthetics. As an example, holes are necessary in order to make ship hatches.

For a plane plate, it is possible and relatively easy to calculate the buckling critical load. However, if the plate is perforated, the use of analytical calculation becomes impracticable.

Many authors have been publishing studies for the last decades about elastic plate buckling. Among those, some of the papers may be highlighted:

El-Sawy and Nasmy (2001) studied the influence of the shape, dimensions and position of the perforations on slender plates submitted to elastic plate buckling phenomenon. The plates had different sizes and were numerically simulated by means the Finite Element Method (FEM).

Shimizu (2007) has showed that, when a plate is perforated, compression stresses appear locally near the hole under a tensile load, and the compression stress may cause local buckling - it's so called tension buckling of the plate.

Moen and Schafer (2009) developed expressions to represent the influence of holes under the critical buckling load in bent or compressed plates. Such expressions were verified through numerical simulations, using the ABACUS software, which is based on the FEM.

Cheng and Zhao (2010) have focused their studies on the cutout-strengthening of perforated steel plates subjected to uniaxial compressive loads.

Real and Isoldi (2010) and Real and Isoldi (2011) studied the elastic buckling phenomenon in thin steel plates analyzing the effect of circular holes dimension and location on its critical load.

So far, the Constructal Design has been used mostly in the Fluid Mechanics and Heat Transfer areas, in order to achieve optimal geometries. Yet, it is also feasible to use it for the Solid Mechanics, once we consider structural elements as systems whose shape may be varied in order to achieve a better stress flow. Furthermore, it is important to highlight the fact that studies about the influence of the Constructal Design and elastic buckling in pursuance of optimal geometries have been developed only by the group of Solid Computational Mechanics from Universidade Federal do Rio Grande (FURG). Among these, we may highlight: Rocha et al. (2012), Rocha et al. (2013) and Isoldi et al. (2013).

Therefore, the main goal of this paper is to evaluate the influence of different type of hole, while seeking the optimal geometry in order to achieve a maximized critical buckling load. For that, the plate's size was kept the same, while the size and geometry of the hole have been modified according to the Constructal Design Method. Two different types of perforations were analyzed:

Persp. Online: exatas \& eng., Campos dos Goytacazes, 20 (08) 127-138 - 2018 
Transversal Oblong and Longitudinal Oblong. These cutouts are centered on a plate which has a width of $H=1 \mathrm{~m}$ and a length of $L=2 \mathrm{~m}$. Previously, a computational model verification was developed in ANSYS ${ }^{\circledR}$ software. This software is based on the Finite Element Method (F.E.M.).

Some examples of oblong cutouts used in offshore structures can be viewed in Fig. 1.

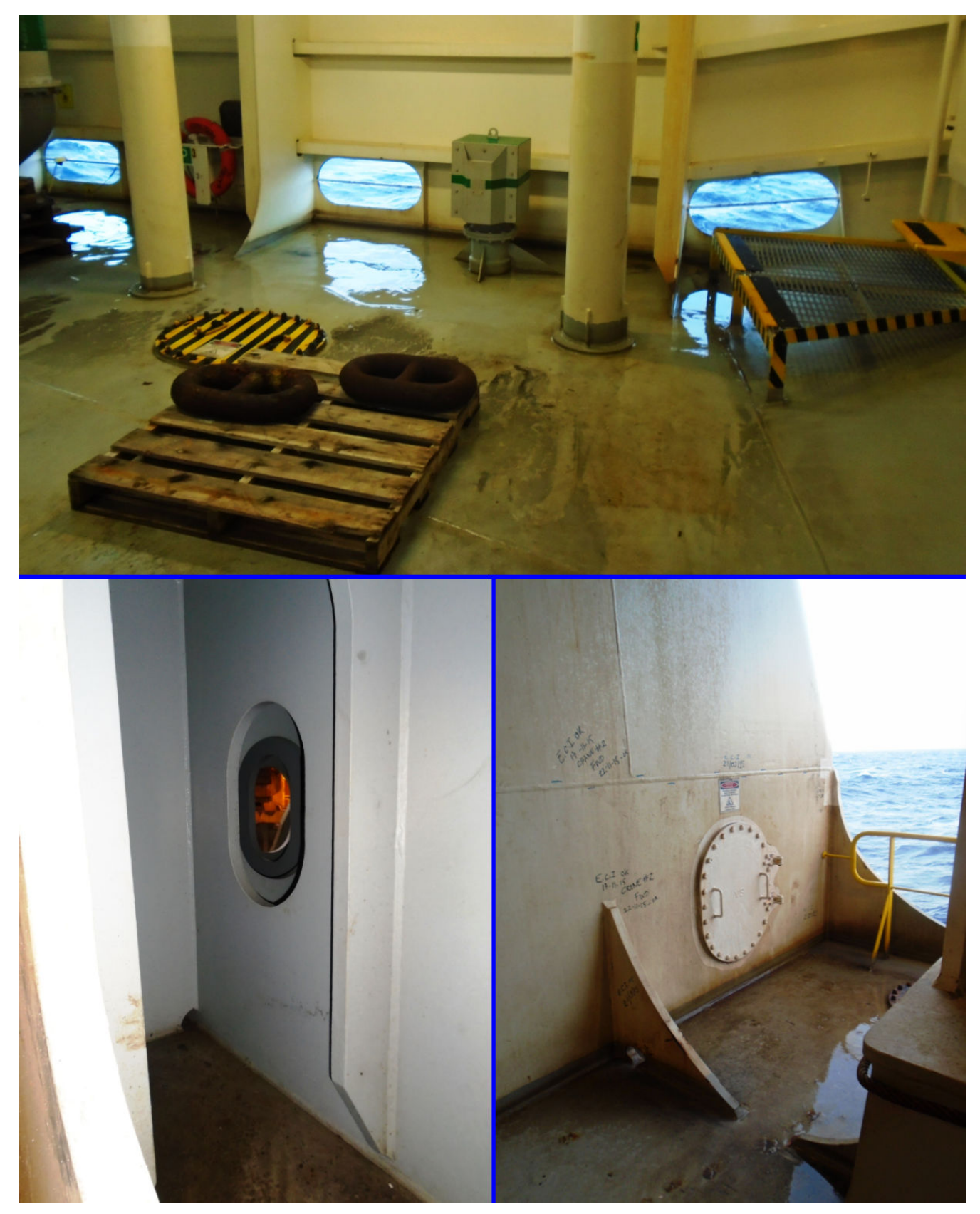

Figure 1. Oblong holes in offshore structures.

\section{METHODOLOGY}

Initially, a solid plate, i.e. a plate with no hole, was analyzed numerically and analytically, evaluating its critical buckling load $P_{c r}$, aiming to verify the computational model developed in the ANSYS software. Moreover, the analytical critical load was adopted as a reference value in the other cases.

Persp. Online: exatas \& eng., Campos dos Goytacazes, 20 (08) 127-138 - 2018 


\subsection{Plate Buckling}

As previously mentioned, in several situations a plate is subjected to uniaxial pressure. The slenderness of these components makes them susceptible to instabilities such as buckling (REAL \& ISOLDI, 2010). Throughout this paper, a slender rectangular steel plate (Young's modulus $E=210$ GPa and Poisson's ratio $n=0.3$ ) will be considered subjected to a compressive axial load P. Its length, width and thickness are $L=2 \mathrm{~m}, H=1 \mathrm{~m}$ and $t=10 \mathrm{~mm}$, respectively. The plate is simply supported on its four edges in the out of plane direction $(z)$ as it is shown on Fig. 2.

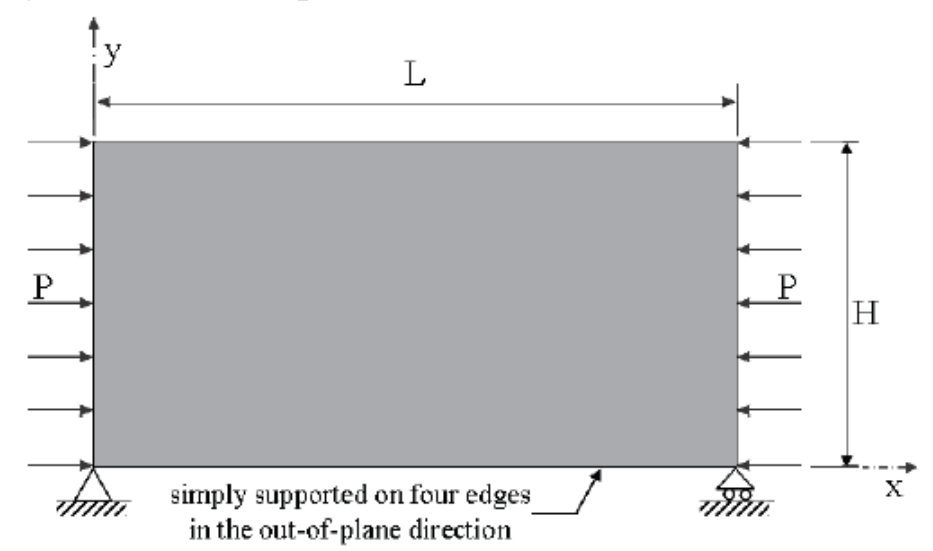

Figure 2. Rectangular solid plate subjected to uniaxial load.

Equation (1) shows the analytical solution in order to determine the critical load of a nonperforated plate, which defines the occurrence of elastic buckling ( $\AA$ KESSON, 2007).

$$
P_{c r}=k \frac{\pi^{2} E t^{3}}{12 H^{2}\left(1-v^{2}\right)}
$$

where $\pi$ is a mathematical constant and $k$ is the buckling coefficient given by Eq. (2):

$$
k=\left(m \frac{H}{L}+\frac{1}{m} \frac{L}{H}\right)^{2}
$$

where $m$ is the number of half waves that occur in the longitudinal direction, therefore, defining the buckling mode of the plate.

Thus, considering that two half waves are generated on the longitudinal direction $(m=2)$, through Eq. (2), we obtain a buckling coefficient $k=4$.0. Nevertheless, through the use of Eq. (2), it is possible to determine the critical buckling load of $P_{c r}=759.20 \mathrm{kN} / \mathrm{m}$ for the plate shown on Fig. 2 .

\subsection{Computational Model}

Through the ANSYS software, the SHELL93 finite element was used in all simulated cases. It has eight nodes and reduced integration. Each node has six degrees of freedom: three translations $\left(u_{x}, u_{y}, u_{z}\right)$ and three rotations $\left(\theta_{x}, \theta_{y}, \theta_{z}\right)$ (ANSYS, 2005).

The elastic eigenvalue analysis was adopted in order to numerically study the buckling phenomenon. The finite elements equilibrium equations for this type of analysis involve the solution of a homogeneous algebraic equation system whose lowest eigenvalue corresponds to the 
critical buckling load and the associated eigenvector represents the first buckling mode of the plate (MOEN \& SCHAFER, 2009).

The formulation used in the analysis includes both linear and non-linear strain components. Thus, the total stiffness matrix $[K]$ is obtained by the sum of the conventional stiffness matrix for small deformations, $[K E]$, with another matrix $[K G]$, called geometrical stiffness matrix. The matrix $[K G]$ not only depends on the geometry but also on the internal forces existing at the beginning of the load, $\{P 0\}$. Then, the total stiffness matrix for a plate at the load level $\{P 0\}$ can be written as (PRZEMIENIECKI, 1985):

$$
[K]=\left[K_{E}\right]+\left[K_{G}\right]
$$

Once the load reaches a level $\{P\}=\lambda\{P 0\}$, where $\lambda$ is a scalar the stiffness matrix can be defined as:

$$
[K]=\left[K_{E}\right]+\lambda\left[K_{G}\right]
$$

The governing equilibrium equations for the plate can be written as:

$$
\left[\left[K_{E}\right]+\lambda\left[K_{G}\right]\right]\{U\}=\lambda\left\{P_{0}\right\}
$$

where $\{U\}$ is the total displacement vector, which may, therefore be given by:

$$
\{U\}=\left[\left[K_{E}\right]+\lambda\left[K_{G}\right]\right]^{-1} \lambda\left\{P_{0}\right\}
$$

At buckling load, the plate presents a large increase in the displacements without a load increase. Through mathematical definition it is possible to determine the inverse matrix as the adjoint matrix divided by the determinant of the coefficients, then the displacements $\{U\}$ tend to infinity when:

$$
\operatorname{det}\left[\left[K_{E}\right]+\lambda\left[K_{G}\right]\right]=0
$$

Equation (7) represents an eigenvalue problem which, once solved, produces the smallest eigenvalue, $\lambda 1$, that corresponds to the critical load $\left\{P_{c r}\right\}=\lambda 1\{P 0\}$ in which buckling occurs. Furthermore, the displacement vector associated $\{U\}$ (eigenvector) defines the buckling mode shape. In the ANSYS software, the eigenvalue/eigenvector problem is solved through the numerical method of Lanczos (ANSYS, 2005).

Finally, to verify the computational model, the critical load of a non-perforated plate was numerically evaluated and the result was compared with the analytical solution given by Eq. (1). The plate was discretized and grid independence was reached through the adoption of a triangular element with a side's size $50.00 \mathrm{~mm}(\mathrm{H} / 20)$, generating a mesh with 1,814 finite elements (Fig. 3a). The numerical result for the critical buckling load was $755.30 \mathrm{kN} / \mathrm{m}$. Therefore, the difference between this approach and the analytical solution $(759.20 \mathrm{kN} / \mathrm{m}$ as earlier mentioned) was $-0.51 \%$, which verifies the computational model for the numerical analysis for linear buckling problems. Figure $3 \mathrm{~b}$ shows the buckling mode of the non-perforated plate. Two half waves were formed, indicated by red ( $z$ positive direction) and blue ( $z$ negative positive direction) colors. 


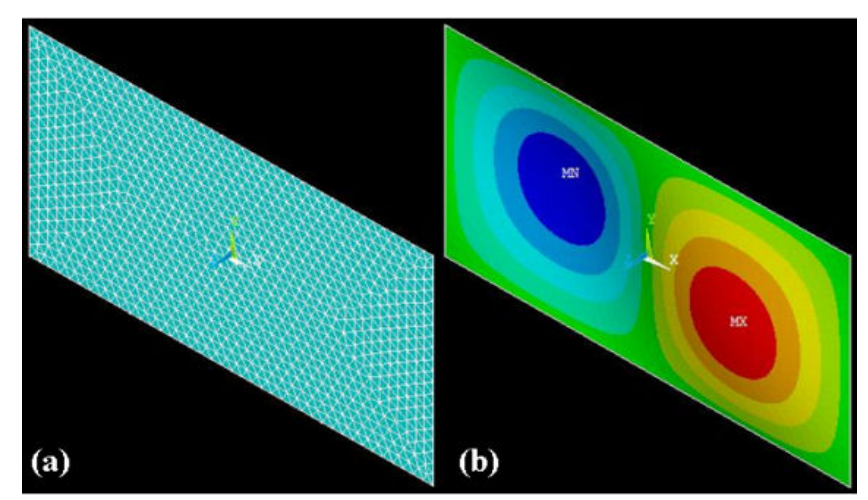

Figure 3. Non-perforated plate: (a) Finite elements mesh; (b) First buckling mode shape

Besides, the computational modeling previously presented was also verified for the analysis of the buckling behavior of thin perforated steel plates. The same plate used in the first verification was studied, however a centered circular hole was considered. In Table 1 the results for the critical buckling load were compared with those obtained by the numerical study developed by the reference, for several hole diameters. As in the first verification an excellent agreement was also obtained here, being $-0.53 \%$ the maximal difference encountered.

Table 1. Comparison of critical buckling load for plate with centered circular hole

\begin{tabular}{cccc}
\hline Hole diameter $(\mathrm{m})$ & $\begin{array}{c}P_{c r}(\mathrm{kN} / \mathrm{m}) \\
\text { El-Sawy and Nazmy (2001) }\end{array}$ & $\begin{array}{c}P_{c r}(\mathrm{kN} / \mathrm{m}) \\
\text { Present work }\end{array}$ & $\begin{array}{c}\text { Difference } \\
(\%)\end{array}$ \\
\hline 0.10 & 766.19 & 763.56 & -0.34 \\
\hline 0.20 & 789.36 & 786.50 & -0.36 \\
\hline 0.30 & 825.08 & 820.87 & -0.51 \\
\hline 0.40 & 849.26 & 847.78 & -0.17 \\
\hline 0.50 & 901.54 & 898.79 & -0.31 \\
\hline 0.60 & 986.46 & 981.22 & -0.53 \\
\hline
\end{tabular}

\subsection{The Constructal Design Method}

In order to apply the Constructal Theory (BEJAN, 2000; BEJAN \& LORENTE, 2008), the Constructal Design Method was used. This method is based on restrictions and objectives. Thereby, the analysis of the influence of the geometries and types of perforation becomes possible. In this paper the holes were centered on the plate and the Constructal Design was used to evaluate the influence of two different types of perforation: Transversal Oblong (Fig. 4a) and Longitudinal Oblong (Fig. 4b). One can notice that Oblong holes are formed by a rectangle with two semicircles on its edges. 

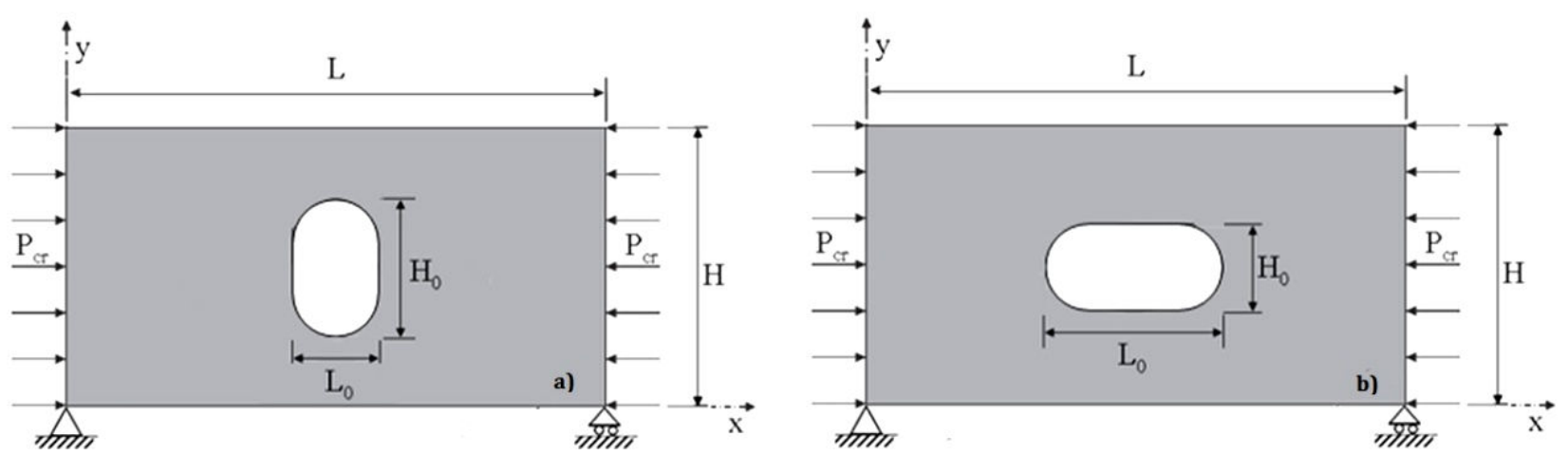

Figure 4. Oblong holes: (a) Transversal; and (b) Longitudinal.

In addition, four different volume fractions $\phi$ were used $(\phi=0.05, \phi=0.08, \phi=0.15$ and $\phi=$ $0.20)$. The volume fraction parameter is defined by the ratio between the hole volume and the total volume of the plate. The volume fraction $(\phi)$ for the Transversal Oblong hole was calculated through Eq. (8):

$$
\phi=\frac{V_{0}}{V}=\frac{\left[\left(H_{0}-L_{0}\right) L_{0}+\pi\left(\frac{L_{0}}{2}\right)^{2}\right] t}{H L t}=\frac{H_{0} L_{0}-L_{0}{ }^{2}+\frac{\pi}{4} L_{0}^{2}}{H L}
$$

Nevertheless, for the Longitudinal Oblong Hole the volume fraction $\phi$ was calculated through Eq. (9):

$$
\phi=\frac{V_{0}}{V}=\frac{\left[\left(L_{0}-H_{0}\right) H_{0}+\pi\left(\frac{H_{0}}{2}\right)^{2}\right] t}{H L t}=\frac{L_{0} H_{0}-H_{0}{ }^{2}+\frac{\pi}{4} H_{0}^{2}}{H L}
$$

Finally, the variation of the hole geometry is defined by the degree of freedom $H_{0} / L_{0}$, which relates the characteristic dimensions of the perforation (see Fig. 4). Its variation must respect a constraint which limits the minimal spacing among hole edges and plate edges, given by: $H-H O=$ $200 \mathrm{~mm}$ and $L-L O=200 \mathrm{~mm}$.

It is important to emphasize that for a specific value of $\phi$, the variation of the ratio $H_{0} / L_{0}$ promotes only a geometric variation in the hole while its volume is kept constant. This fact allows a consistent comparison among different hole geometries.

\section{RESULTS AND DISCUSSION}

In all the simulated cases, the material and mesh type were the same as the ones used in the procedure of the verification of the computational model.

In order to normalize the comparisons among the results, an dimensionless critical load $\left(P_{c r}, \operatorname{dim}\right)$ was used. $P_{c r}$, dim is defined by the relationship between the critical load of the perforated plate and the critical load of the non-perforated plate. Figure 5 shows the variation of $P_{c r}$, dim for each volume fraction according to the degree of freedom $H_{0} / L_{0}$. 


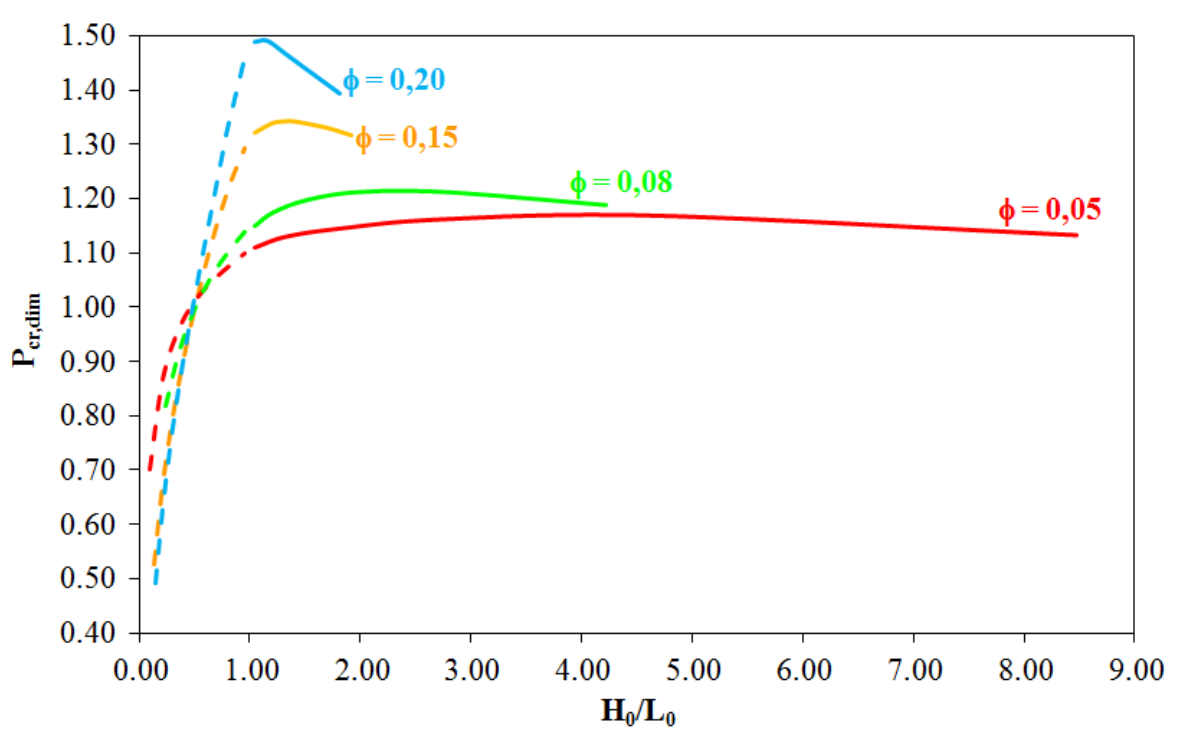

Figure 5. Magnitudes of $P_{c r, d i m}$ due to $H_{0} / L_{0}$ variation.

On Figure 5, for each different $\phi$, the dashed lines represent the Longitudinal Oblong holes, and the continuous lines represent the Transversal Oblong ones. Thus, it is possible to infer that both types of holes complement each other. For $0.00<H_{0} / L_{0}<1.00$ the oblong hole is defined as longitudinal, while for $H_{0} / L_{0}>1.00$ the oblong hole is transversal. If a value of $H_{0} / L_{0}=1$ was considered, then a circular hole would be generated. One can also note that the $P_{c r}$, dim maximum for the Longitudinal Oblong cutouts is always obtained with $H_{0} / L_{0}=0.95$. On the other hand, for the Transversal Oblong perforations an intermediate value of the ratio $H_{0} / L_{0}$ conducts to the $P_{c r}$, dim maximized. Furthermore, for all volume fractions, the Transversal Oblong holes reached a higher critical load in comparison to the longitudinal oblong holes. Figure 5 also shows that the lower the value of the volume fraction $\phi$, the higher is the number of possibilities for $H_{0} / L_{0}$., being this observation in agreement with the Constructal Design Method.

Another important observation from Fig. 5 is that the variation of the ratio $H_{0} / L_{0}$ also promotes the obtainment of critical loads lower and higher than the critical load of the plate with no hole, i.e. the geometry (shape) of the perforation can improve or worsen the plate mechanical behavior. This aspect is in agreement with already published researches as: Real and Isoldi (2010), Real and Isoldi (2011), Rocha et al. (2012), Rocha et al. (2013) and Isoldi et al. (2013).

Considering the Longitudinal Oblong perforations with $\phi=0.20$ (see Fig. 5), it is possible to observe in Fig. 6 the buckling mode for the plates with lowest and highest values of H0/L0, where the blue, yellow and red colors are representing, respectively, the minimum (negative z direction), null and maximum (positive $\mathrm{z}$ direction) displacements.
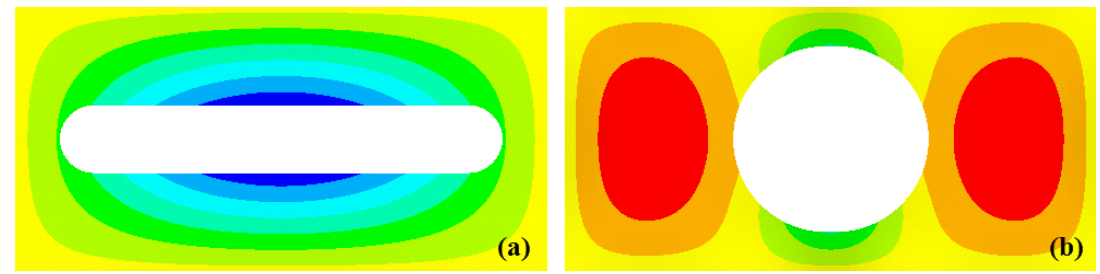

Figure 6. Buckling mode of plates with Longitudinal Oblong cutout and $\phi=0.20$ : (a) $H_{0} / L_{0}=0.15$ and (b)

$$
\left(H_{0} / L_{0}\right) o=0.95 \text {. }
$$

From Fig. 6 we can understand the influence of the hole geometry in the mechanical behavior of the plates, once for $H_{0} / L_{0}=0.15$ (Fig. 6a) only one half wave is formed while for $\left(H_{0} / L_{0}\right) o=0.95$

Persp. Online: exatas \& eng., Campos dos Goytacazes, 20 (08) 127-138 - 2018 
(Fig. 6b) the buckled configuration of the plate is formed with three half waves. Therefore, a great critical load is required to form three half waves in the plate, explaining why the ratio $\left(H_{0} / L_{0}\right) o=$ 0.95 is the optimized geometry in this case.

In a similar way, the geometry variation influence in the elastic buckling behavior of the plates with Transversal Oblong perforation and $\phi=0.20$ (see Fig. 5) can be viewed in Fig. 7. Figures 7a, $7 \mathrm{~b}$ and $7 \mathrm{c}$ show, respectively, the Transversal Oblong holes with $H_{0} / L_{0}=1.05,\left(H_{0} / L_{0}\right) \mathrm{o}=1.16$ and $H_{0} / L_{0}=1.81$. The same color scale of Fig. 6 is used.
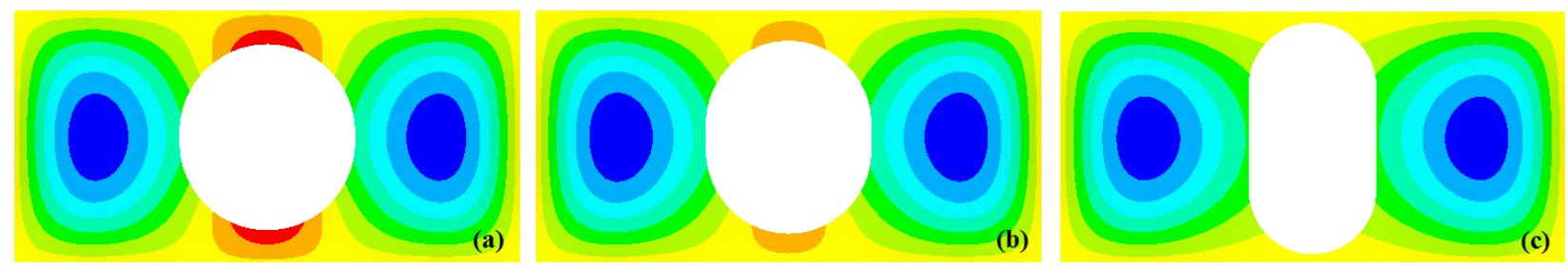

Figure 7. Buckling mode of plates with Transversal Oblong cutout and $\phi=0.20$ : (a) $H_{0} / L_{0}=1.05$, (b) $\left(H_{0} / L_{0}\right) \mathrm{o}=1.16$ and (c) $H_{0} / L_{0}=1.81$.

One can notice that in Figs. 7a and 7b three half waves are formed, while in Fig. 7c two half waves are generated. The geometric configuration with $\left(H_{0} / L_{0}\right) \mathrm{o}=1.16$ is the optimal shape in this case, however the difference between its critical load and the critical load reached with $H_{0} / L_{0}=1.05$ is very small. This fact explain the resemblance in buckling modes presented in Figs. 7(a) and 7(b).

In addition, some aspects observed on Fig. 5 are easier to perceive on Figs. 8 and 9 when, respectively, the values of the optimized geometries, $\left(H_{0} / L_{0}\right) o$, and the values of the maximized dimensionless critical loads, $\left(P_{c r}, \operatorname{dim}\right)_{\mathrm{m}}$, are plotted as a function of the hole volume fraction, $\phi$, variation.

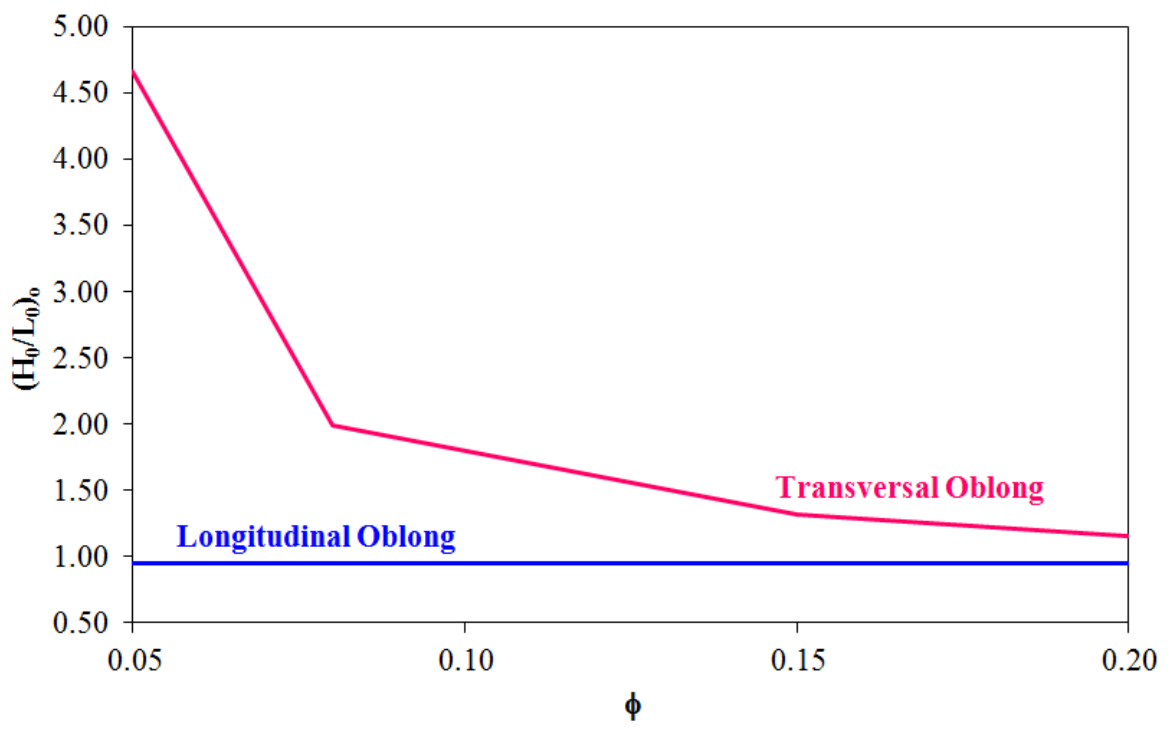

Figure 8. Optimal geometries for each hole volume fraction. 


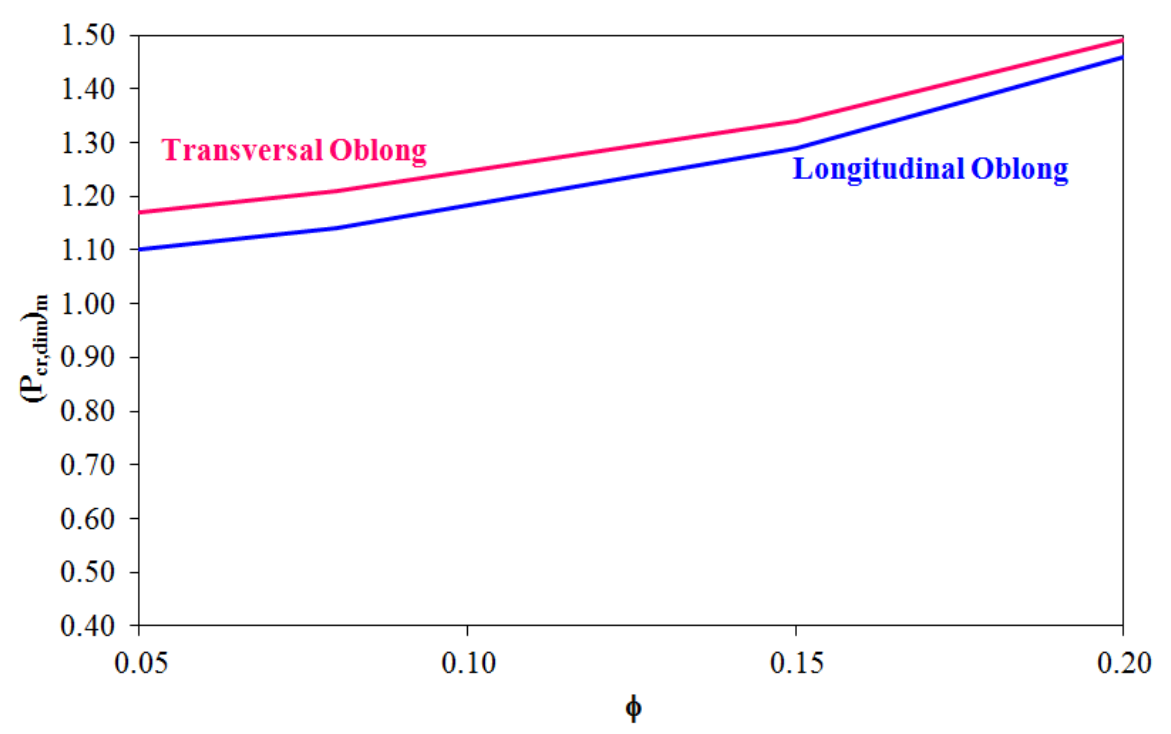

Figure 9. Maximum dimensionless critical buckling load for each hole volume fraction.

On Fig. 8, it is possible to notice that the optimal critical load was obtained when $H_{O} / L_{O}=0,95$ for all the different volume fractions for the Longitudinal Oblong hole, as already observed in Fig. 5. Whereas, considering the Transversal Oblong cutout, for $\phi=0.05$ the optimal load was achieved with a very higher $\left(H_{O} / L_{O}\right) o=4.66$ when compared to the degree of freedom $\left(H_{O} / L_{O}\right) o=1.16$ for $\phi=0.20$.

From Fig. 9 it is possible to observe that, for both types of perforations, the increase of the hole size (or the increase of the hole volume fraction) promotes a rise in the magnitude of the critical buckling load. This behavior can also be explained by means the analysis of the buckled configuration of plates. For example, considering the optimized geometries for the Transversal Oblong cutout with the extreme values of hole volume fraction, it is evident in Fig. 10a that when $\phi=0.05$ there is two half wave formation while in Fig. $10 \mathrm{~b}$ for $\phi=0.20$ are generated three half waves. Highlighting that in Fig. 10 the blue, green and red colors represent, respectively, the minimum (negative $z$ direction), null and maximum (positive $z$ direction) displacements.
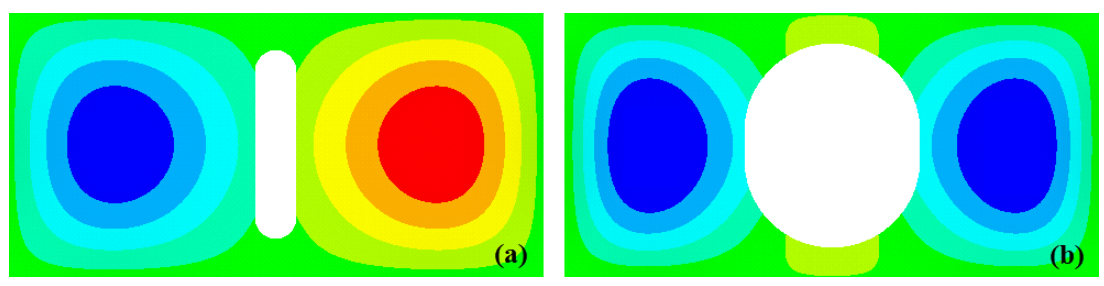

Figure 10. Buckling mode of plates with Transversal Oblong cutout: (a) $\phi=0.05$ and $\left(H_{0} / L_{0}\right) o=4.66$ and (b) $\phi=0.20$ and $\left(H_{0} / L_{0}\right) o=1.16$.

Finally, it is worth to emphasize that all results presented in this work were obtained considering the elastic buckling, i.e. a linear elastic material behavior was taken into account. Therefore, these results are rigorously valid only if the calculated critical buckling load does not cause normal stresses above the material's yielding stress, when it is applied to the plate. If the yielding stress limit is surpassed, a nonlinear finite element analysis (elasto-plastic buckling analysis) should be performed, including geometrical and material nonlinearities. 


\section{CONCLUSIONS}

In order to evaluate the influence of type, shape and size of perforations in the elastic buckling behavior of thin steel plates, the Constructal Design Method allied to the numerical simulation were applied. To do so, rectangular plates with centered Oblong Transversal and Oblong Longitudinal perforations were considered. The shape of the cutout was varied by the degree of freedom $H_{0} / L_{0}$ (ratio between the characteristics dimensions of the hole) while its size was changed by the hole volume fraction $(\phi)$ parameter (ratio between the hole volume and the total plate volume).

The results obtained indicated that for the same hole type and the same hole volume fraction the variation of the perforation geometry promoted by the ratio $H_{0} / L_{0}$ can conduct to a superior mechanical performance, which in this case is the increase of the critical buckling load. Improvements of until around $200 \%$ were noticed only due to the geometric variation of the hole.

With regard of the hole size, the variation of the $\phi$ parameter indicates, for the studied cases, that higher values for the critical load can be achieved with the increase of the hole size, being this fact relates with the stress redistribution caused by the hole presence in the plates.

In addition, the comparison between the Oblong Transversal and Oblong Longitudinal hole types shows that Transversal Oblong perforation allows to reach higher critical loads for all studied hole volume fractions.

Therefore, the application of the Constructal Design associated with the computational modeling can be a powerful tool for the structural engineering analysis.

\section{REFERENCES}

ÅKESSON, B., 2007. Plate buckling in bridges and other structure. Taylor \& Francis.

ANSYS User's Manual (version 10.0), 2005. Swanson Analysis System Inc, Houston. Cambridge.

BEJAN, A., 2000, Shape and structure, from engineering to nature, Cambridge University Press,

BEJAN, A., \& LORENTE, S., 2008, Design with Constructal Theory, Wiley, Hoboken.

CHENG, \& ZHAO, J., 2010. "Strengthening of perforated plates under uniaxial compression: Buckling analysis," Thin-Walled Structures, Vol. 48, pp. 905-914.

EL-SAWY, K.M. \& NAZMY, A.S., 2001."Effect of aspect ratio on the elastic buckling of uniaxially loaded plates with eccentric holes," Thin-Walled Structures, Vol. 39 , pp. 983-998.

ISOLDI, L. A. ; REAL, M. V. ; CORREIA, A. L. G. ; VAZ, J. ; SANTOS, E. D. DOS ; ROCHA, L. A. O., 2013. "Flow of Stresses: Constructal Design of Perforated Plates Subjected to Tension or Buckling. In: Constructal Law and the Unifying Principle of Design" - Rocha, L. A. O. ; Lorente, S.; Bejan, A.. (Org.). Understanding Complex Systems. 1ed.New York: Springer New York, v. 1, p. 195-217.

MOEN, D. \& SCHAFER, B. W., 2009. "Elastic buckling of thin plates with holes in compression or bending," Thin-Walled Structures, Vol. 47, pp. 1597-1607.

PRZEMIENIECKI, J.S., 1985 Theory of Matrix Structural Analysis. Ed. Dover Publications.

REAL, M.V. \& ISOLDI L. A., 2010. "Finite element buckling analysis of uniaxially loaded plates

Persp. Online: exatas \& eng., Campos dos Goytacazes, 20 (08) 127-138 - 2018

seer.perspectivasonline.com.br 
with holes," in Southern Conference on Computational Modeling (MCSul), Universidade Federal do Rio Grande, Rio Grande, pp. 69-73.

REAL, M.V. \& ISOLDI L. A., 2011. "Effect of circular holes dimension and location on the elastic buckling load of rectangular plates," in Brazilian Congress of Mechanical Engineering (COBEM), Universidade Federal do Rio Grande do Norte, Natal, pp. 1-10.

ROCHA, LUIZ ALBERTO O. ; REAL, M. V. ; CORREIA, A. L. G. ; VAZ, J. ; DOS SANTOS, E. D. ; ISOLDI, L. A., 2012 . "Geometric optimization based on the Constructal Design of perforated thin plates subject to buckling". Computational Thermal Sciences, v. 4, p. 119-129.

ROCHA, L. A. O. ; ISOLDI, L. A. ; REAL, M. V. ; DOS SANTOS, E. D. ; CORREIA, A. L. G. ; BISERNI, C. ; LORENZINI, G., 2013. "Constructal design applied to the elastic buckling of thin plates with holes". Central European Journal of Engineering, v. 3, p. 475-483. 827-833.

SHIMIZU, S., 2007, “Tension Buckling of Plate Having a Hole". Thin-Walled Structures, v. 45, p.

YAMAGUCHI, E., 1999. "Basic Theory of Plates and Elastic Stability” 